\title{
Inhibitory effects of novel isothiocyanate derivative on proliferation and invasion of glioma U251 cells and regulation of circRNAs and IncRNAs
}

\author{
Yu Zhu ${ }^{1}$ and Ping Yang ${ }^{1}$ \\ ${ }^{1}$ Department of Clinical Laboratory, Tianjin Huanhu Hospital, Tianjin Key Laboratory of Cerebral Vessels and Neural \\ Degeneration, Tianjin 300350, P.R. China \\ Correspondence to: Yu Zhu, email: zhuyutj@126.com \\ Ping Yang, email: tjhhhospitallab@126.com \\ Keywords: glioma; isothiocyanate; IncRNAs; circRNAs; proliferation
}

Received: November 08, $2017 \quad$ Accepted: December 26, $2017 \quad$ Published: January 02, 2018

Copyright: Zhu et al. This is an open-access article distributed under the terms of the Creative Commons Attribution License 3.0 (CC BY 3.0), which permits unrestricted use, distribution, and reproduction in any medium, provided the original author and source are credited.

\section{ABSTRACT}

Gliomas proliferation and invasion plays the critical roles in the tumor progression. Isothiocyanate is the hydrolysis products of Brassica vegetables and suppress many types of tumor including gliomas. We design and synthesized an isothiocyanate derivative by computer-aided drug design base on alkylglycerone phosphate synthase (AGPS) to improve targeting and explore its effect on the proliferation, invasion, apoptosis, cell cycle, and the expression of circular RNAs (circRNAs) and long non-coding RNAs (IncRNAs) in U251 cell line. The isothiocyanate derivative suppressed proliferation and invasion by inducing apoptosis with improving the activity of caspase-3/8 and blocked the cell cycle at G2/M phase and regulating the expression of circRNAs and IncRNAs involved in the above biological behavior in human glioma U251 cells. Our results showed the effect of isothiocyanate derivative on the anti-tumor activity, which shows potential for application as a anti-glioma drug.

\section{INTRODUCTION}

Glioma is one of the most common malignant tumors seriously damaging human's health. Although major advances have been made in the study of relevant clinical treatments, the prognosis is still not ideal [1]. Tumor metastasis is one of the primary reasons for treatment failure. Clinically, nearly half of the patients were diagnosed with advanced glioma, and there was the metastasis [2]. Therefore, it is of great significance to develop new drugs to inhibit proliferation and metastasis. It was considered that circular RNAs (circRNAs) [3] and long non-coding RNAs (lncRNAs) [4] were an important role in tumor process, changed expression of them could improve or suppress the potential of proliferation and invasion in glioma. Therefore, it is considered that circRNAs and lncRNAs were important target of tumor, including glioma.

Isothiocyanate is the hydrolysis products of Brassica vegetables [5]. Many previous studies of isothiocyanate were conducted on the apoptosis and inhibit proliferation and metastasis of tumor cells [6]. We also found that it could inhibit the expression of alkylglycerone phosphate synthase (AGPS) which was an oncogene and the proliferation and invasion of tumor cells can be inhibited and the drug sensibility of drug resistant cells can be improved by AGPS silencing in our previous study [7-8], meanwhile, we found that AGPS silencing could regulate the expression of circRNAs and lncRNAs of U251 cell line (data was not published).

We design and synthesized isothiocyanate derivative by CADD (computer-aided drug design) (data was not showed) targeting AGPS which was the new compound un-reported, predicted the ADME (absorption, distribution, metabolism, excretion) and toxicity, and investigates the inhibitory effect of the isothiocyanate derivative on the proliferation and invasion of glioma U251 cells, providing the basis for further development and clinical application of isothiocyanate derivative. 


\section{RESULTS}

\section{Virtual screening, ADME and toxicity prediction results}

With Virtual screening and prediction, the isothiocyanate derivative can have a good combination with AGPS cavity and ADME/ toxicity, and amino acid residues form hydrogen bond and hydrophobic effect with nitrogen, sulfur atom and carbon sulfur covalent bond, meanwhile, the other substituent residues in micromolecules can form a certain hydrogen bonding interaction with their surrounding residues to a certain extent (Table 1). Ideal drug parameter reference range for ADME: a, 7.0 200.0; b, $-2.0 \sim 6.5 ; \mathrm{c},-6.5 \sim 0.5 ; \mathrm{d}, \sim 25$ is bad, $\sim 500$ was good.

\section{Effects of isothiocyanate derivative on the proliferation and expression of AGPS in U251 cells}

The proliferation inhibition rate of U251 cells with different concentrations of isothiocyanate derivative was shown in (Figure 1A). With the increase of drug concentration, the inhibitory effect gradually increased, with significant concentration - effect relation and the IC50 was $73.4 \mu \mathrm{M}$ for $24 \mathrm{~h}$. We used the non-toxic concentration $(5 \mu \mathrm{M})$ (inhibition rate $<5 \%)$ and lowtoxic concentration $(10 \mu \mathrm{M})$ (inhibition rate $<15 \%)$ to following research to avoid the affect of cell proliferation inhibition, the $0 \mu \mathrm{M}$ was the control group. The mRNA of AGPS was not significant decreased with $5 \mu \mathrm{M}$ and $10 \mu \mathrm{M}$ isothiocyanate derivative treatment (Figure 1B).

\section{Effects of isothiocyanate derivative on the invasion of $\mathrm{U} 251$ cells}

With the increase of the concentration of isothiocyanate derivative, the invasive cells were decreased. Compared with the control group, the results showed that the isothiocyanate derivative could inhibit the invasion of U251 cells with certain dependence of concentration (Figure 2).

\section{Effects of isothiocyanate derivative on the cell cycle and apoptosis of $\mathrm{U} 251$ cells}

Compared with the control group, with the increase of drug concentration, the G2/M phase of U251 cells was increased (Figure 3A), and the apoptosis cell was significantly increased (Figure 3B), conforming to flow cytometry results. At same time, the activity of caspase- $3 / 8$ was improved (Figure 3C).

\section{Effects of isothiocyanate derivative on the expression of circRNAs and IncRNAs}

After treatment of U251 cells with different concentrations of isothiocyanate derivative for $24 \mathrm{~h}$, compared with the control group, with the increase of drug dosage, the expression of circRNAs and lncRNAs was significant differences, however, the expression of AGPS was not significant changed (Figure 4).

\section{DISCUSSION}

One of the main reasons for the failure of glioma therapy is metastasis, and the control of metastasis is one of the key factors to determine the prognosis of
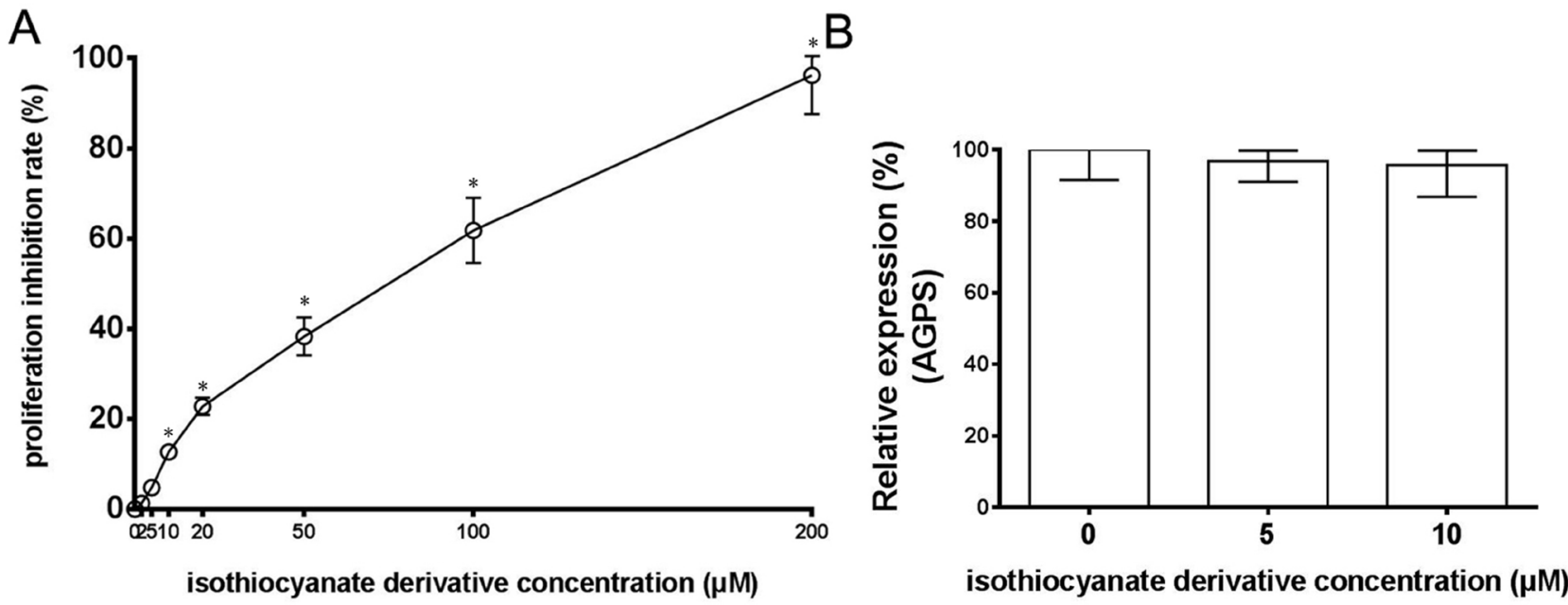

Figure 1: Effects of isothiocyanate derivative on the proliferation and expression of AGPS in U251 cells. (A) The effect of isothiocyanate derivative on the proliferation in U251 cells. "compared with $0 \mu \mathrm{M}$ group, $P<0.05$. (B) Effects of isothiocyanate derivative on the mRNA expression of AGPS in U251 cells. 
Table 1: The structure and comination model of isothiocyante derivative

\begin{tabular}{l} 
2D combination model \\
\hline 3D combination model
\end{tabular}

patients. The occurrence of tumor metastasis includes cell proliferation, adhesion, invasion and others, with complex mechanism [9]. Currently, the anticancer study of nature compound has been concerned [10]. However, there were also some weakness need to overcome. The structure reform was a method to improve compound property. Since a lower stability of isothiocyanate, we design its derivative to improve the stability by CADD, meanwhile, we investigated the effect of isothiocyanate derivative on the proliferation and invasion in U251 cells.

With vitro experiment MTS assay, this experiment confirmed that isothiocyanate derivative can inhibit the proliferation of glioma U251 cell, with concentration dependence. Invasion was the key part of tumor
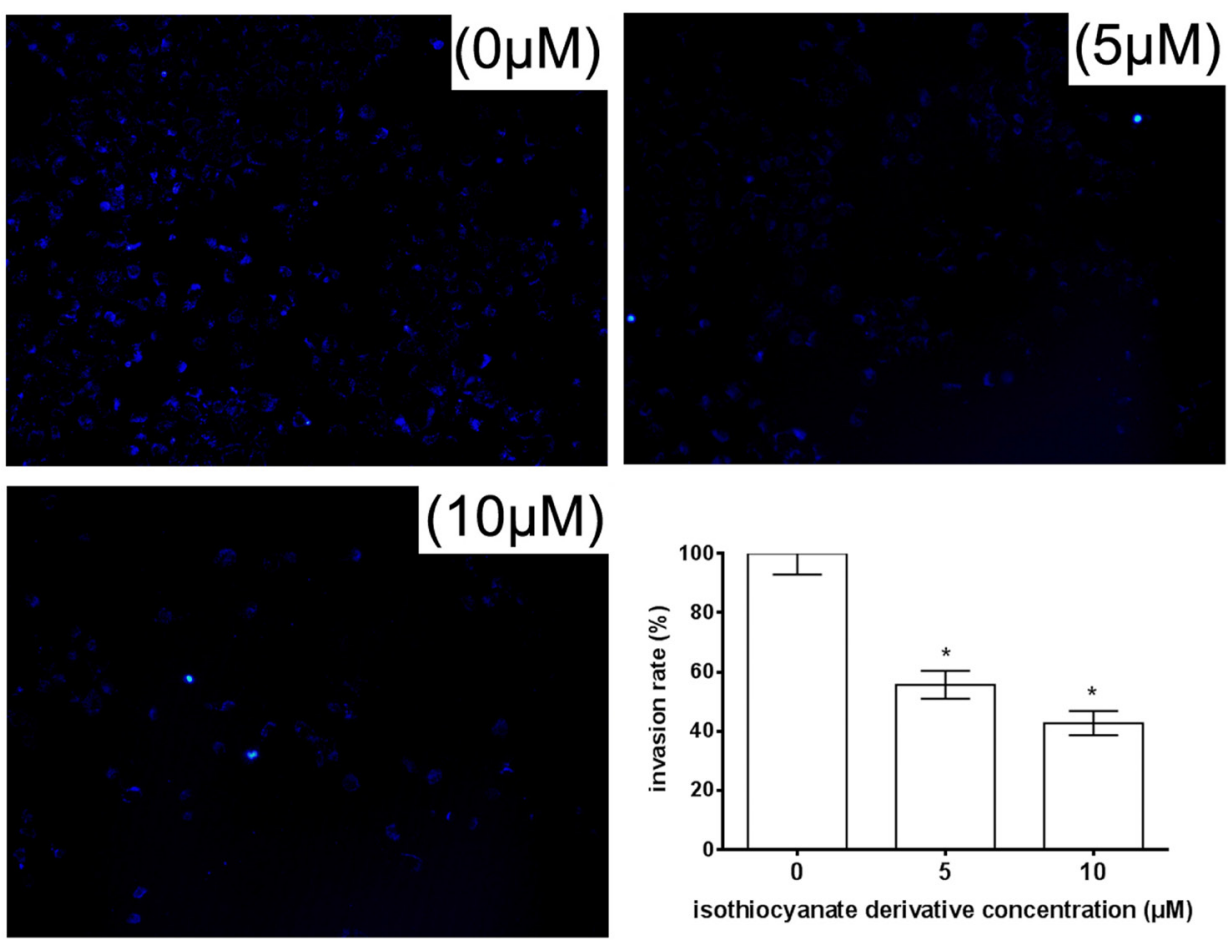

isothiocyanate derivative concentration $(\mu \mathrm{M})$

Figure 2: Effects of isothiocyanate derivative on the invasion of $\mathbf{U} 251$ cells. ${ }^{*}$ compared with $0 \mu \mathrm{M}$ group, $P<0.05$. 
metastasis, we also found that isothiocyanate derivative can inhibit the invasion of glioma in non-toxic $(5 \mu \mathrm{M})$ and low- toxic concentration $(10 \mu \mathrm{M})$. However, the mRNA expression of AGPS was not significant decreased, suggesting the anti-tumor of isothiocyanate derivative was not from the decreased expression of AGPS. Therefore, the results showed that isothiocyanate derivative was a potential anti-tumor drug which need to explore the mechanism. Cell cycle arrested and apoptosis should be the one of the mechanism of isothiocyanate derivative due to it could induce cell cycle arrested and apoptosis.

Tumor cells existed a variety of circRNAs and lncRNAs, playing a key role in promoting tumor cell proliferation and metastasis [11-12]. Our study showed that AGPS silencing could regulate the expression of following circRNAs and lncRNAs of U251 cell line (data was not published) and we have confirmed that isothiocyanate derivative could suppress the expression of circRNAs circUBAP2, cZNF292, circHIPK3, circTCF25 and Cdr1, and lncRNAs H19, DQ786243, HOXD-AS1, CCAT1 and HULC, which were the oncogene [13-22]. Meanwhile, it improved the expression of circRNAs circZKSCAN1, circMTO1 and circITCH, and lncRNAs GAS5, CASC2, ANCR and MEG3, which were the tumor suppressor gene [23-30]. Above regulation of circRNAs and lncRNAs was same as the AGPS silencing.
A
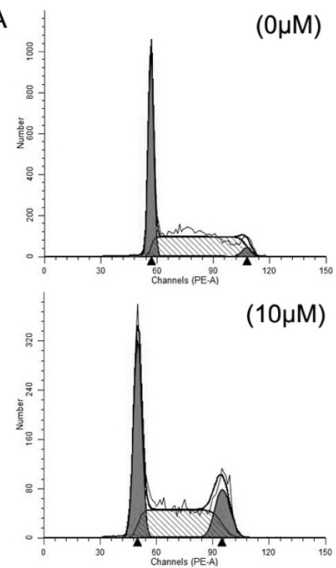
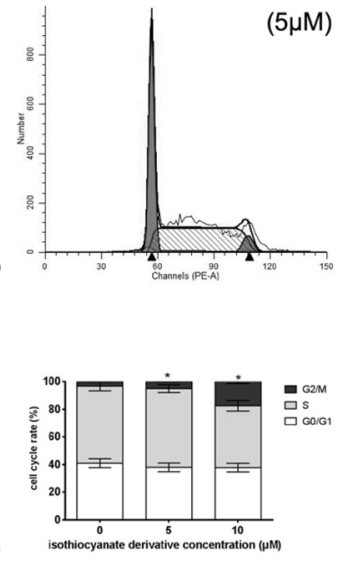
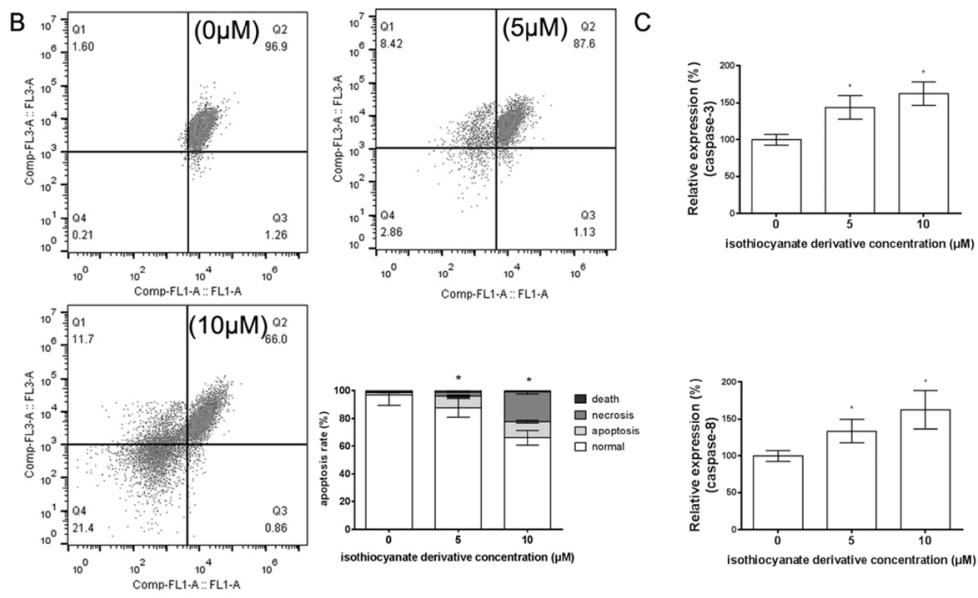

Figure 3: Effects of isothiocyanate derivative on the cell cycle and apoptosis of U251 cells. (A) Effects of isothiocyanate derivative on the cell cycle of U251 cells. "compared with $0 \mu \mathrm{M}$ group, $P<0.05$. (B) Effects of isothiocyanate derivative on the apoptosis of U251 cells. "compared with $0 \mu \mathrm{M}$ group, $P<0.05$. (C) Effects of isothiocyanate derivative on the activity of caspase-3/8 of U251 cells. "compared with $0 \mu \mathrm{M}$ group, $P<0.05$.
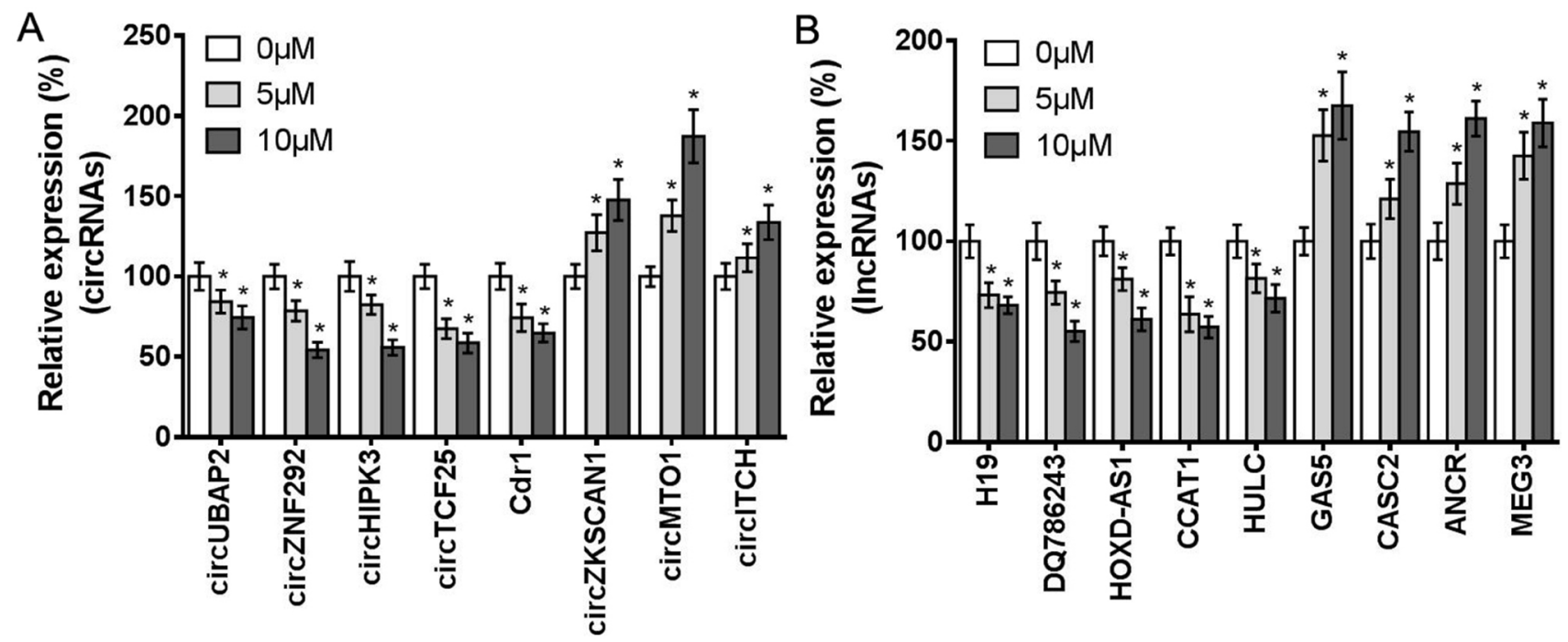

Figure 4: Effects of isothiocyanate derivative on the expression of circRNAs and IncRNAs of U251 cells. (A) Effects of isothiocyanate derivative on the expression of circRNAs of U251 cells. "compared with $0 \mu \mathrm{M}$ group, $P<0.05$. (B) Effects of isothiocyanate derivative on the expression of lncRNAs of U251 cells. "compared with $0 \mu \mathrm{M}$ group, $P<0.05$. 
In a word, isothiocyanate derivative inhibits the proliferation and invasion, induce cell cycle arrested and apoptosis, regulating the expression of circRNAs and lncRNAs may be one of its regulation mechanisms. We also explored the effect of the isothiocyanate derivative on the anti-tumor activity in hepatic carcinoma, lung cancer, breast cancer and so on, it will be showed in further article.

\section{MATERIALS AND METHODS}

\section{Virtual screening}

AGPS three-dimensional structure model (PDBID:2UUV) was downloaded from PDB Bank and the micromolecular structure was draw by ChemBioOffice2010. "CDOCKER ENERGY" was measured by Discovery Studio 3.5 and the ADME including $\log \mathrm{Po} / \mathrm{w}$ (oil-water partition coefficient), PSA (polarization surface area), $\log$ S (water solubility) and PMDCK (permeability Maden Darby Canine Kidney), meanwhile, toxicity including rodent carcinogenicity,mutagenicity, skin irritancy, ocular irritation, aerobic biodegradability, were predicted by Schrodinger Suite 2009 software.

\section{Cell culture}

U251 cell line was provided by American Type Culture Collection (USA). The medium was the DMEM medium with $10 \%$ fetal bovine serum (FBS) (Gibco). The cells were cultured in the cell incubator with $5 \% \mathrm{CO}_{2}$ at $37^{\circ} \mathrm{C}$.

\section{MTS assay}

$5 \times 10^{3} \mathrm{U} 251$ cells suspension was added in 96well plates for $24 \mathrm{~h}$, and isothiocyanate derivative with different concentrations $(0,2,5,10,20,50,100,200$ $\mu \mathrm{M})$ was added for $24 \mathrm{~h}$. Then the cell proliferation was measured by MTS assay. Inhibition rate $/ \%=(1-\mathrm{OD}$ value treatment group $/$ OD value control group $) \times 100 \%$.

\section{Transwell assay}

Matrigel was added on Transwell upper chamber. U251 cells $\left(2 \times 10^{4}\right.$ cells $/$ well $)$ with 5 and $10 \mu \mathrm{M}$ isothiocyanate was added in the upper chamber, and the culture medium with $10 \%$ fetal bovine serum was added in the lower chamber for $16 \mathrm{~h}$ in $5 \% \mathrm{CO}_{2}$ at $37^{\circ} \mathrm{C}$. Then the membrane was fixed with paraformaldehyde, stained with $100 \mathrm{ng} / \mathrm{ml}$ DAPI (2-(4-Amidinophenyl)-6indolecarbamidine dihydrochloride) for $10 \mathrm{~min}$, the cells were counted under the microscope $(\times 200)$ at $488 \mathrm{~nm}$ with the average.

\section{Cell cycle assay}

$3 \times 10^{5} \mathrm{U} 251$ cells suspension was added in 6-well plates for $24 \mathrm{~h}$, and 5 and $10 \mu \mathrm{M}$ isothiocyanate derivative was added for $24 \mathrm{~h}$ in $5 \% \mathrm{CO}_{2}$ at $37^{\circ} \mathrm{C}$. Then cells were digested, fixed by $70 \%$ alcohol at $4^{\circ} \mathrm{C}$, and cells were stained with propidium iodide (PI) at room temperature darkly. The cell cycle was measured by FACSAria flow cytometry (BD Biosciences) at $488 \mathrm{~nm}$.

\section{Cell apoptosis assay}

$3 \times 10^{5} \mathrm{U} 251$ cells suspension was added in 6-well plates for $24 \mathrm{~h}$, and 5 and $10 \mu \mathrm{M}$ isothiocyanate derivative was added for $24 \mathrm{~h}$ in $5 \% \mathrm{CO}_{2}$ at $37^{\circ} \mathrm{C}$. Then cells was digested and stained with Annexin V-FITC/PI at room temperature darkly. The cell apoptosis was measured by FACSAria flow cytometry (BD Biosciences) at $488 \mathrm{~nm}$.

\section{Caspase-3/8 activity assay}

To investigate the cellular activity of caspase-3/8, $3 \times 10^{5} \mathrm{U} 251$ cells suspension was added in 6-well plates for $24 \mathrm{~h}$, and 5 and $10 \mu \mathrm{M}$ isothiocyanate derivative was added for $24 \mathrm{~h}$ in $5 \% \mathrm{CO}_{2}$ at $37^{\circ} \mathrm{C}$. The cellular activity of caspase-3/8 was measured according to the manual's instruction by FLICA Caspase Detection Kits (ImmunoChemistry Technologies) using a microplate reader.

\section{Realtime PCR assay}

$3 \times 10^{5}$ U251 cells suspension was added in 6-well plates for $24 \mathrm{~h}$, and 5 and $10 \mu \mathrm{M}$ isothiocyanate derivative was added for $24 \mathrm{~h}$ in $5 \% \mathrm{CO}_{2}$ at $37^{\circ} \mathrm{C}$. Cell total RNA was extracted by TRIzol reagent (Invitrogen). Total RNA was then reverse transcribed and expression of mRNAs, circRNAs and lncRNAs were detected using real-time PCR assay. The PCR conditions were as follows: denaturation at $95^{\circ} \mathrm{C}$ for $10 \mathrm{~min}$, followed by 40 cycles at $95^{\circ} \mathrm{C}$ for $15 \mathrm{~s}, 60^{\circ} \mathrm{C}$ for $60 \mathrm{~s}$ and a final elongation at $95^{\circ} \mathrm{C}$ for $15 \mathrm{~s}, 60^{\circ} \mathrm{C}$ for $60 \mathrm{~s}$ and $95^{\circ} \mathrm{C}$ for $15 \mathrm{~s}$. The expression levels of the genes were normalized to that of the housekeeping gene $\beta$-actin, as a control. The full details of the primers used in these experiments are shown in (Table 2).

\section{Statistical analysis}

The experimental data are statistically analyzed with SPSS 11.0 statistical software (SPSS Inc., IL, USA) and data is expressed with mean \pm SD. The statistical analysis was performed using one-way ANOVA with the Tukey-Kramer multiple comparisons test. $P<0.05$ was considered statistically significant. 
Table 2: The primers used in the study

\begin{tabular}{|c|c|}
\hline Gene & Primer sequences $\left(5^{\prime}-3^{\prime}\right)$ \\
\hline \multirow{2}{*}{ AGPS } & Forward: ACCAGATTCCCTGGAGTTCA \\
\hline & Reverse: GAACCACCAGGTCCTCGATA \\
\hline \multirow{2}{*}{ DQ786243 } & Forward: AATCGGCTCTGGAAGGTGAA \\
\hline & Reverse: CTGCTGTTCCGATGGTGTCTT \\
\hline \multirow{2}{*}{ HOXD-AS1 } & Forward: GGCTCTTCCCTAATGTGTGG \\
\hline & Reverse: CAGGTCCAGCATGAAACAGA \\
\hline \multirow{2}{*}{ CCAT1 } & Forward: CATTGGGAAAGGTGCCGAGA \\
\hline & Reverse: ACGCTTAGCCATACAGAGCC \\
\hline \multirow{2}{*}{ HULC } & Forward: CAGGAAGAGTCGTCACGAGAACCAG \\
\hline & Reverse: CTTCTTGCTTGATGCTTTGGTCTGT \\
\hline \multirow{2}{*}{ GAS5 } & Forward: CTTCTGGGCTCAAGTGATCCT \\
\hline & Reverse: TTGTGCCATGAGACTCCATCAG \\
\hline \multirow{2}{*}{$\mathrm{CASC} 2$} & Forward: GCACATTGGACGGTGTTTCC \\
\hline & Reverse: CCC AGTCCTTCACAGGTCAC \\
\hline \multirow{2}{*}{ ANCR } & Forward: GACATTTCCTGAGTCGTCTTCGAACGGAC \\
\hline & Reverse: TAGTGCGATTTAGAGCTGTACAAGTTTC \\
\hline \multirow{2}{*}{ MEG3 } & Forward: TTTTGTGCCCAAGGCTCCTGGA \\
\hline & Reverse: AGGGACTCAAGGAGCCAGGTTA \\
\hline \multirow{2}{*}{ circUBAP2 } & Forward: AGCCTCAGAAGCCAACTCCTTTG \\
\hline & Reverse: TCAGGTTGAGATTTGAAGTCAAGAT \\
\hline \multirow{2}{*}{ circZNF292 } & Forward: GCTCAAGAGACTGGGGTGTG \\
\hline & Reverse: AGTGTGTGTTCTGGGGCAAG \\
\hline \multirow{2}{*}{ circTCF25 } & Forward: CGGAATTCTGAAATATGCTATCTTACAGAGAGAGCGCTGTACAGCATGGA \\
\hline & Reverse: CGGGATCCTCAAGAAAAAATATATTCACCTCCAGGGAACATGGTGAGCGC \\
\hline \multirow{2}{*}{ circHIPK3 } & Forward: TATGTTGGTGGATCCTGTTCGGCA \\
\hline & Reverse: TGGTGGGTAGACCAAGACTTGTGA \\
\hline \multirow{2}{*}{ circCdr1 } & Forward: GTGTCTCCAGTGTATCGGCG \\
\hline & Reverse: TACTGGCACCACTGGAAACC \\
\hline \multirow{2}{*}{ circZKSCAN1 } & Forward: AGTCCCACTTCAAACATTCGTCT \\
\hline & Reverse: CACCTTCACTATTACGATACCATCC \\
\hline \multirow{2}{*}{ circITCH } & Forward: GCAGAGGCCAACACTGGAA \\
\hline & Reverse: TCCTTGAAGCTGACTACGCTGAG \\
\hline \multirow{2}{*}{ MTO1 } & Forward: GAGCTGTAGAAGATCTTATTC \\
\hline & Reverse: CACAGGCCATCCAAGGCATC \\
\hline \multirow{2}{*}{$\beta$-actin } & Forward: AGGCACCAGGGCGTGAT \\
\hline & Reverse: GCCCACATAGGAATCCTTCTGAC \\
\hline
\end{tabular}

\section{ACKNOWLEDGMENTS}

None.

\section{CONFLICTS OF INTEREST}

No potential conflicts of interest are disclosed.

\section{GRANT SUPPORT}

This study was supported by National Natural Science Foundation of China (Grant No.31501159),
Tianjin Public Health Key Research Project (Grant No.15KG108), Special Program of Talents Development for Excellent Youth Scholars in Tianjin, China (Grant No. TJTZJH-QNBJRC-2-9).

\section{REFERENCES}

1. Mondal A, Kumari Singh D, Panda S, Shiras A. Extracellular Vesicles As Modulators of Tumor Microenvironment and Disease Progression in Glioma. Front Oncol. 2017; 7:144.

2. Galante JR, Rodriguez F, Grossman SA, Strowd RE. Late post-treatment radiographic changes 3 years 
following chemoradiation for glioma: the importance of histopathology. CNS Oncol. 2017; 6:195-201.

3. Song X, Zhang N, Han P, Moon BS, Lai RK, Wang $\mathrm{K}, \mathrm{Lu}$ W. Circular RNA profile in gliomas revealed by identification tool UROBORUS. Nucleic Acids Res. 2016; 44:e87.

4. Lin TK, Chang CN, Tsai CS, Huang YC, Lu YJ, Chen WJ, Lin YH, Chung IH, Lin KH. The long non-coding RNA LOC441204 enhances cell growth in human glioma. Sci Rep. 2017; 7:5603.

5. Wieczorek MN, Walczak M, Skrzypczak-Zielińska M, Jeleń HH. Bitter taste of Brassica vegetables: the role of genetic factors, receptors, isothiocyanates, glucosinolates and flavor context. Crit Rev Food Sci Nutr. 2017; 1-11. https://doi.org/ 10.1080/10408398.2017.1353478.

6. Liu X, Takano C, Shimizu T, Yokobe S, Abe-Kanoh N, Zhu B, Nakamura T, Munemasa S, Murata Y, Nakamura Y. Inhibition of phosphatidylinositol 3-kinase ameliorates antiproliferation by benzyl isothiocyanate in human colon cancer cells. Biochem Biophys Res Commun. 2017; 491:209-216.

7. Zhu Y, Liu XJ, Yang P, Zhao M, Lv LX, Zhang GD, Wang Q, Zhang L. Alkylglyceronephosphate synthase (AGPS) alters lipid signaling pathways and supports chemotherapy resistance of glioma and hepatic carcinoma cell lines. Asian Pac J Cancer Prev. 2014; 15:3219-26.

8. Zhu Y, Zhu L, Lu L, Zhang L, Zhang G, Wang Q, Yang P. Role and mechanism of the alkylglycerone phosphate synthase in suppressing the invasion potential of human glioma and hepatic carcinoma cells in vitro. Oncol Rep. 2014; 32:431-36.

9. Tang W, Liang R, Duan Y, Shi Q, Liu X, Liao Y. PLD1 overexpression promotes invasion and migration and function as a risk factor for Chinese glioma patients. Oncotarget. 2017; 8:57039-46. https://doi.org/10.18632/ oncotarget. 18961.

10. Pinheiro R, Braga C, Santos G, Bronze MR, Perry MJ, Moreira R, Brites D, Falcão AS. Targeting Gliomas: Can a New Alkylating Hybrid Compound Make a Difference? ACS Chem Neurosci. 2017; 8:50-59.

11. O'Leary VB, Smida J, Matjanovski M, Brockhaus C, Winkler K, Moertl S, Ovsepian SV, Atkinson MJ. The circRNA interactome-innovative hallmarks of the intraand extracellular radiation response. Oncotarget. 2017; 8:78397-409. https://doi.org/10.18632/oncotarget.19228.

12. Nowicki-Osuch K, Li Y, Challinor M, Gerrard DT, Hanley NA, Sharrocks AD. EINCR1 is an EGF inducible lincRNA overexpressed in lung adenocarcinomas. PLoS One. 2017; 12:e0181902.

13. Chen S, Bu D, Ma Y, Zhu J, Chen G, Sun L, Zuo S, Li T, Pan Y, Wang X, Liu Y, Wang P. H19 Overexpression Induces Resistance to $1,25(\mathrm{OH}) 2 \mathrm{D} 3$ by Targeting VDR Through miR-675-5p in Colon Cancer Cells. Neoplasia. 2017; 19:226-36.
14. Shan T, Fan J, Zhao Q, Deng K, Xia J. Upregulation of long non-coding RNA DQ786243 promotes the progression of gastric cancer. Mol Med Rep. 2017; 16:3761-68.

15. Lu S, Zhou J, Sun Y, Li N, Miao M, Jiao B, Chen H. The noncoding RNA HOXD-AS1 is a critical regulator of the metastasis and apoptosis phenotype in human hepatocellular carcinoma. Mol Cancer. 2017; 16:125.

16. Zhu H, Zhao H, Zhang L, Xu J, Zhu C, Zhao H, Lv G. Dandelion root extract suppressed gastric cancer cells proliferation and migration through targeting lncRNACCAT1. Biomed Pharmacother. 2017; 93:1010-17.

17. Kong D, Wang Y. Knockdown of lncRNA HULC inhibits proliferation, migration, invasion and promotes apoptosis by sponging miR-122 in osteosarcoma. J Cell Biochem. 2018;119:1050-1061.

18. Zhang H, Wang G, Ding C, Liu P, Wang R, Ding W, Tong D, Wu D, Li C, Wei Q, Zhang X, Li D, Liu P, et al. Increased circular RNA UBAP2 acts as a sponge of miR-143 to promote osteosarcoma progression. Oncotarget. 2017; 8:61687-97. https://doi.org/10.18632/oncotarget.18671.

19. Yang P, Qiu Z, Jiang Y, Dong L, Yang W, Gu C, Li G, Zhu Y. Silencing of cZNF292 circular RNA suppresses human glioma tube formation via the $\mathrm{Wnt} / \beta$-catenin signaling pathway. Oncotarget. 2016; 7:63449-55. https://doi. org/10.18632/oncotarget.18671.

20. Zhong Z, Lv M, Chen J. Screening differential circular RNA expression profiles reveals the regulatory role of circTCF25-miR-103a-3p/miR-107-CDK6 pathway in bladder carcinoma. Sci Rep. 2016; 6:30919.

21. Zheng Q, Bao C, Guo W, Li S, Chen J, Chen B, Luo Y, Lyu D, Li Y, Shi G, Liang L, Gu J, He X, Huang S. Circular RNA profiling reveals an abundant circHIPK3 that regulates cell growth by sponging multiple miRNAs. Nat Commun. 2016; 7:11215.

22. Yu L, Gong X, Sun L, Zhou Q, Lu B, Zhu L. The Circular RNA Cdrlas Act as an Oncogene in Hepatocellular Carcinoma through Targeting miR-7 Expression. PLoS One. 2016; 11:e0158347.

23. Yang Y, Shen Z, Yan Y, Wang B, Zhang J, Shen C, Li T, Ye C, Gao Z, Peng G, Ye Y, Jiang K, Wang S. Long non-coding RNA GAS5 inhibits cell proliferation, induces G0/G1 arrest and apoptosis, and functions as a prognostic marker in colorectal cancer. Oncol Lett. 2017; 13:3151-58.

24. Wang Y, Liu Z, Yao B, Li Q, Wang L, Wang C, Dou C, Xu M, Liu Q, Tu K. Long non-coding RNA CASC2 suppresses epithelial-mesenchymal transition of hepatocellular carcinoma cells through CASC2/miR-367/FBXW7 axis. Mol Cancer. 2017; 16:123.

25. Li Z, Dong M, Fan D, Hou P, Li H, Liu L, Lin C, Liu J, Su L, Wu L, Li X, Huang B, Lu J, Zhang Y. LncRNA ANCR down-regulation promotes TGF- $\beta$-induced EMT and metastasis in breast cancer. Oncotarget. 2017; 8:67329-43. https://doi.org/10.18632/oncotarget.18622. 
26. Li L, Shang J, Zhang Y, Liu S, Peng Y, Zhou Z, Pan H, Wang X, Chen L, Zhao Q. MEG3 is a prognostic factor for CRC and promotes chemosensitivity by enhancing oxaliplatin-induced cell apoptosis. Oncol Rep. 2017; 38:1383-92.

27. Zhu L, Yang N, Chen J, Zeng T, Yan S, Liu Y, Yu G, Chen Q, Du G, Pan W, Li X, Zhou H, Huang A, Tang H. LINC00052 upregulates EPB41L3 to inhibit migration and invasion of hepatocellular carcinoma by binding miR-452-5p. Oncotarget. 2017; 8:63724-37. https://doi. org/10.18632/oncotarget.18892.

28. Yao Z, Luo J, Hu K, Lin J, Huang H, Wang Q, Zhang P, Xiong Z, He C, Huang Z, Liu B, Yang Y. ZKSCAN1 gene and its related circular RNA (circZKSCAN1) both inhibit hepatocellular carcinoma cell growth, migration, and invasion but through different signaling pathways. Mol Oncol. 2017; 11:422-37.

29. Wan L, Zhang L, Fan K, Cheng ZX, Sun QC, Wang JJ. Circular RNA-ITCH Suppresses Lung Cancer Proliferation via Inhibiting the Wnt/ $\beta$-Catenin Pathway. BioMed Res Int. 2016; 2016:1579490.

30. Han D, Li J, Wang H, Su X, Hou J, Gu Y, Qian C, Lin Y, Liu X, Huang M, Li N, Zhou W, Yu Y, Cao X. Circular RNA MTO1 acts as the sponge of miR-9 to suppress hepatocellular carcinoma progression. Hepatology. 2017; 66:1151-64. 